\title{
ENTREVISTA
}

\section{La aplicación de la ley sobre represión de la masonería y el comunismo en el País Valenciano: los masones de Alicante y Castellón (1938-1963)}

El investigador Vicent Sampedro Ramo ha defendido una Tesis Doctoral, cuyo título es "La aplicación de la ley sobre represión de la masonería y el comunismo en el País Valenciano: los masones de Alicante y Castellón (1938-1963)" en la Universidad Jaume I de Castelló en España, el 22 de enero de 2016, bajo la dirección de los profesores Rosa Monlleó Peris, Catedrática de E.U. de la Universitat Jaume I de Castelló y José Miguel Santacreu Soler, Catedrático de Universidad de la Universitat d'Alacant. Vicent Sampedro Ramo nació en 1962 en Brasil.

El autor nos ha concedido la siguiente entrevista.

¿Cuáles fueron los motivos que le llevó a enfocar su investigación hacia la Masonería?

Mi interés por la masonería proviene de una casualidad. En 1982, siendo estudiante de $2^{\circ}$ en la Facultat de Geografía e Historia de la Universitat de València, llegó a mis manos el extra IV de la revista Historia 16, publicado en noviembre 1977, coordinado por el profesor Ferrer Benimeli, sobre la historia de la masonería y este tema me apasionó. Gracias a la mediación del profesor Joan Brines Blasco, del Departament d'Història Contemporània de Valencia, entré en contacto con los dos máximos especialistas del momento en la historia de la masonería española, los profesores José Antonio Ferrer Benimeli, de la Universidad de Zaragoza y Pedro Álvarez Lázaro, de la Universidad Pontificia de Comillas que iban a asistir como ponentes al I Coloquio "España bajo el Franquismo", que se celebró en noviembre de 1984 en Valencia. Ambos me animaron a comenzar la investigación y el profesor Álvarez Lázaro me propuso un tema de investigación, la masonería en Alicante, en concreto los orígenes de esta institución en esa ciudad durante el Sexenio Democrático y los primeros años de la Restauración y además, ambos avalaron, ese mismo año, mi ingreso como socio numerario del Centro de Estudios Históricos de la Masonería Española (CEHME) del que continúo formando parte en la actualidad.

En mayo de 1986 defendí con éxito ante un tribunal presidido por el profesor Ferrer Benimeli, mi tesis de licenciatura, dirigida por Dr. Brines, sobre la aparición y desarrollo de las dos primeras logias documentadas que aparecieron en Alicante, la logia Alona $\mathrm{n}^{\mathrm{o}} 44, \mathrm{y}$ la Puritanos $\mathrm{n}^{\mathrm{o}} 1 \mathrm{y} \mathrm{n}^{\mathrm{o}} 68$ en el periodo comprendido entre 1870 y 1882.

Durante los años siguientes, continué la investigación sobre la masonería en el País Valenciano, aunque profesionalmente soy funcionario de administración de la Universitat 
de València, aunque de manera intermitente, pero procurando participar en la mayor parte de los Simposia que el CEHME ha venido celebrando. En 2007, me integré en un grupo de investigadores sobre la represión franquista organizado en Valencia por Acció Cultural del P.V., la "Comissió de la Veritat", con miembros de diversas universidades valencianas y también de Cataluña y Baleares. Animado por quienes serían mis directores de Tesis, los doctores Rosa Monlleó y José Miguel Santacreu, retomé el doctorado, trasladando mi expediente a la Universitat Jaume I de Castelló, en donde en septiembre de 2011 defendí un nuevo trabajo de investigación titulado titulado La lucha por un ideal: Julio Cervera Baviera, republicano y masón, dirigido por la profesora Monlleó, que me permitió la obtención del D.E.A. y a continuación inscribí el proyecto de Tesis Doctoral, que este año he defendido ante un Tribunal presidido por el Dr. Luis P. Martín, catedrático de la Universidad de Pau, del que también formaban parte los profesores Leandro Álvarez Rey, catedrático de la Universidad de Sevilla y Rosana Gutiérrez Lloret, catedrática de la Universidad de Alicante, que calificaron la tesis con Sobresaliente Cum Laude.

En un principio, cuando realizamos la inscripción del proyecto de Tesis Doctoral, pensábamos circunscribirnos únicamente a la etapa represiva de la masonería de Alicante y Castellón en la posguerra, pero a lo largo del proceso de investigación nos hemos dado cuenta de que era imprescindible estudiar el desarrollo de las logias masónicas en estas dos provincias, desde la crisis de finales de la década de 1890 hasta el inicio de la guerra civil, precisamente para poder identificar a los masones que luego fueron represaliados.

¿Cuáles fueron las fuentes que ha utilizado?

En cuanto a la documentación empleada, la base fundamental son los legajos y expedientes que se guardan en el Centro Documental de la Memoria Histórica de Salamanca. Legajos correspondientes a logias, triángulos y organismos masónicos superiores y fundamentalmente los expedientes personales de los masones y los sumarios incoados por el Tribunal Especial de Represión de la Masonería y el Comunismo.

Ha sido importante no centrarnos solo en una faceta de la represión que afectaba a los masones, sin duda la más importante, como fue la emanada desde el Tribunal Especial que los juzgó por el delito de masonería. La represión fue pluriforme y por ello hemos intentado averiguar en la medida de lo posible como afectaron a los masones de Alicante y Castellón las otras vertientes de la represión, especialmente los expedientes de Responsabilidades Políticas, los sumarios de la Jurisdicción Militar e incluso los expedientes de depuración laboral. Para ello hemos consultado diferentes expedientes de Responsabilidades Políticas procedentes del Arxiu Provincial de Castelló y del Arxiu del Regne de València y referencias sobre los consejos de guerra sumarísimos de urgencia que se incoaron contra algunos masones, depositados en el Archivo Histórico de la Defensa de Madrid. 
Consideramos crucial el estudio de la prensa del momento, de la que hemos hecho un amplio uso, facilitado por su consulta a través de la red, especialmente en lo referente a la prensa alicantina del periodo 1893-1939. También hemos consultado el diario del movimiento de Castellón, Mediterráneo, en los primeros años del franquismo. Las referencias hemerográficas han sido muy numerosas a lo largo de todo el trabajo.

Hemos empleado una metodología transdisciplinar, ensanchando las vías de interpretación, aumentando la fiabilidad de los análisis y estableciendo diferentes conexiones, tal y como ha señalado el profesor Luis P. Martín, partiendo del planteamiento de que la masonería es una sociedad, con una serie de características propias, que practica y regula unos hábitos y modela un tipo de sociabilidad propio, estableciendo una serie de comportamientos sociales diferenciadores.

En esta línea, no es necesaria una metodología propia, sino que se debe aplicar en cada momento y circunstancia los recursos que nos aporta la historiografía actual, poniendo en relación la masonería con la historia cultural, la social o la política de una manera transversal.

Para nosotros, la interrelación masonería-política es un eje fundamental en la investigación, pues las logias fueron lugar de refugio y encuentro de los elementos progresistas, donde eran transmitidos una serie de valores que se encarnaban en el ideal republicano.

Si bien hemos dado un orden cronológico a la investigación, hemos ido interrelacionando constantemente la información obtenida de la documentación masónica con la situación sociopolítica en las diferentes etapas de la vida de las logias, fundamentalmente en el caso de Alicante, por ser más global y duradero en el tiempo. En el caso de Castellón la masonería tuvo un carácter mucho más localista y alejado del centro de poder y decisión que era la capital de la provincia, por lo que no ha sido posible realizar de la misma forma este tipo de interrelaciones.

¿Cuáles fueron las principales dificultades con las que se ha encontrado? ¿Cómo las ha superado?

Una cuestión fundamental en nuestro estudio ha sido la identificación de los masones, que serán las víctimas de la represión franquista. Y esa ha sido la tarea más ardua, debido a un problema insoluble, como es la desaparición de la mayor parte de la extensa documentación producida por las logias de Alicante y Castellón durante el siglo XX. Ha sido una empresa compleja la elaboración de una base de datos de masones del País Valenciano, que hemos ampliado también a los de la provincia de Valencia. que en la actualidad comprende, para la provincia de Alicante un total de 2.050 masones en el periodo 1870-1939, de los que 656 tuvieron actividad durante algún periodo del siglo Xx. En cuanto a la provincia de Valencia tenemos datados un total de 2.098 masones, durante el mismo periodo, de los que 681 
estuvieron en activo en algún momento del siglo XX. Como podemos observar, las cifras son muy similares en ambas provincias. De la provincia de Castellón nos hemos ceñido al siglo XX y a una serie de destacados masones de la época anterior, así como a masones castellonenses en activo en logias fuera de la provincia. Esto nos da un resultado de 105 individuos, de los que 52 estarán en activo en algún momento del siglo XX, Estas cifras nos pueden dar una idea de lo que significó, numéricamente, la represión franquista en el País Valenciano.

Durante todos estos años hemos desarrollado una labor de búsqueda e investigación, partiendo en primer lugar de los cuadros lógicos conservados, ninguno de ellos elaborado con posterioridad a 1931, que pacientemente hemos ido completando con los libros de actas, las planchas conservadas, la documentación de los expedientes personales, una vez identificado el masón y también con la documentación procedente de los sumarios de la represión, así como con numerosas referencias hemerográficas y bibliográficas.

¿Cuáles fueron las principales problemáticas históricas que su trabajo ha resuelto?

Una de las hipótesis fundamentales de este trabajo en este periodo, ha sido la incidencia e importancia de la masonería alicantina en la reorganización del republicanismo alicantino que se desarrolló entre finales de 1902 y principios de 1903, que sentó las bases de la Unión Republicana en Alicante, pues la masonería alicantina no cesó en sus trabajos con la crisis finisecular, aunque a partir de 1907 entró en una etapa de decadencia, que llevó en 1909 a la desaparición de toda actividad masónica en Alicante, periodo que se extendió hasta 1913, con la vuelta a los trabajos de la logia Constante Alona. Esta etapa coincidirá con un nuevo proyecto político que conformará el primer gran bloque de izquierdas, la Conjunción Republicano-Socialista y con la recuperación electoral del republicanismo, todos los esfuerzos irían encaminados al combate político y por ello se abandonaron las actividades masónicas. Desde 1913 y especialmente a partir de 1917 se iniciarán en Constante Alona algunos de los más carismáticos líderes de lo que será el republicanismo alicantino en las dos décadas siguientes. Nuestra hipótesis es que la masonería vuelve a tener auge precisamente cuando la crisis política del republicanismo fue un hecho, a partir de 1915, con un claro retroceso electoral.

Serán los políticos republicanos, especialmente los jóvenes, quienes llamarán a las puertas de la masonería sobre todo entre 1920 y 1924. Confluirán en Constante Alona y posteriormente también en los otros talleres que se fueron creando, republicanos radicales, reformistas y autónomos, volviendo a ser la logia el nexo de unión, la base de esa sociabilidad progresista y avanzada, en un momento de recesión del republicanismo político.

Durante los años de la Dictadura de Primo de Rivera, las logias de Alicante ven nutridas sus filas con elementos refractarios al sistema político imperante, lo que influirá en 
que se consolide una parte importante de la oposición al régimen, que participará activamente en los movimientos insurreccionales. Los masones alicantinos serán los dirigentes de la Alianza Republicana y formarán parte fundamentalmente de Acción Republicana y del Partido Republicano Radical Socialista y a partir de 1934, de Izquierda Republicana y de Unión Republicana Nacional.

Al mismo tiempo se realizará una labor de proselitismo en la provincia, que fructificó con la creación de logias y triángulos en Denia, Elche, Alcoi y Elda, en los que ingresarán los elementos más significados del republicanismo local.

Con el advenimiento de la Segunda República y la presencia de masones entre sus principales dirigentes, vemos cómo irán ocupando cargos de responsabilidad en el nuevo Gobierno y su presencia en la política y los partidos en este periodo, lo que implicó un descenso moderado de la actividad masónica, especialmente en los líderes republicanos.

En cuanto a la masonería de la provincia de Castellón, durante el periodo 19051936, solo aparecen cinco talleres de escasa entidad y con un número reducido de masones en activo, no más de 33, a los que hay que sumar otros castellonenses miembros de logias de Madrid o Valencia. A diferencia de Alicante, el núcleo masónico en la provincia de Castellón en estos años se centrará fundamentalmente en Nules y Vila-real, en el periodo 1924-1931. Posteriormente solo aparecerá un pequeño triángulo en Torreblanca.

Uno de los objetivos principales de esta tesis doctoral ha sido, como hemos dicho, la identificación de los masones de las provincias de Castellón y Alicante, que fueron en su práctica totalidad víctimas de la represión franquista. La guerra supuso un elevado número de víctimas entre los masones alicantinos, víctimas de la represión durante la guerra y la posguerra o fallecidos en bombardeos. Hemos contabilizado un total de 20 masones o antiguos masones que fallecieron en estas circunstancias.

Hemos analizado en profundidad un total de 385 sumarios del TERMC, que nos han permitido establecer unos parámetros válidos en cuanto a la represión franquista. La práctica totalidad de los masones de estas dos provincias les fue incoado un sumario por delito de masonería, siendo muy contadas las excepciones, producidas por errores de identificación o por falta de datos fehacientes sobre la iniciación efectiva, que en algunos casos se había producido, aunque la Sección Especial de la DERD, no pudo encontrar las pruebas suficientes.

A pesar de que en teoría, la Ley era muy clara en cuanto a los castigos a aplicar, la arbitrariedad en las decisiones del Tribunal Especial fue bastante habitual, dándose casos en los que siendo prácticamente semejante el supuesto delito de masonería, según el momento en que fuera juzgado, la logia a la que perteneciera o, muy importante, el año en el que se produjeran las actuaciones, el resultado variaba en función de las decisiones del Tribunal.

Planteamos pues la hipótesis de que el Tribunal fue más duro e implacable con los masones a los que se juzgó entre 1941 y 1943. Que primero se persiguió a quienes ostentaron cargos públicos de relieve, como los diputados o gobernadores civiles y a 
quienes habían detentado altos cargos en la masonería con grados elevados. Y no solo en la aplicación de las penas, sino especialmente en el cumplimiento efectivo de la condena y en la aplicación de la prisión condicional o prisión atenuada en el domicilio.

Las condenas en rebeldía fueron más abundantes entre los miembros de las logias de la ciudad de Alicante que entre las logias ubicadas en localidades más pequeñas, cuyo nivel de masones exiliados fue mucho menor. Se exiliaron los que tuvieron responsabilidades políticas fundamentalmente. Pero incluso cuando fueron regresando a España, en ocasiones muchos años después, se vieron sometidos a la actuación del Tribunal Especial.

Al mismo tiempo planteamos que en general a pesar de la dureza de las penas, con excepción de los condenados en el primer bienio de actuación del Tribunal, el cumplimiento efectivo de las penas fue muy limitado y que en general los condenados a partir de 1944 no solían ser encarcelado. Solo en un $15 \%$ de los sumarios estudiados, los masones condenados sufrieron prisión efectiva y en 1946 fueron liberados los últimos masones de estas dos provincias encarcelados.

¿Por favor, podría resumir la esencia de su Tesis en dos líneas?

La esencia de la Tesis la podemos resumir en la profunda interrelación de la masonería y el republicanismo en Alicante durante todo el periodo investigado y la inmisericorde actuación de la represión franquista, que sin embargo, debe ser matizada en su justa medida.

¿Cuáles fueron las lecciones, a todos los niveles, personal y profesional, que usted ha deducido de su experiencia investigativa?

A nivel personal estamos hablando de una investigación de 30 años, que, con altibajos siempre ha estado presente, teniendo en cuenta que ha sido un proceso fuera del ámbito universitario, en el que me he implicado emocionalmente en un grado muy elevado. Por mi profesión, únicamente he podido contar con mis periodos vacacionales y mi tiempo libre para dedicarlo a la investigación. Sin embargo ésta me ha enriquecido enormemente, pues mi objetivo final ha sido sacar a los masones, víctimas de la represión franquista, de la fosa del olvido a la que fueron condenados y devolverles la dignidad que les fue arrebatada por la dictadura.

¿Ahora, cuáles son sus proyectos profesionales?

Fundamentalmente terminar la investigación de la totalidad de los sumarios de masones de Alicante y los de Valencia. La Tesis, por su amplitud (1.160 páginas) queremos que sea publicada por partes, un primer volumen dedicado a los masones de Castellón y en cuanto a 
Alicante, un volumen con la historia de la masonería en la provincia entre 1893 y 1939 y posteriormente, uno sobre la represión franquista. Tenemos el proyecto de realizar un diccionario biográfico de los masones valencianos del siglo XX, incluyendo por supuesto a los masones de la provincia de Valencia.

¿Quisiera destacar algún aspecto que no se ha contemplado y que usted consideraría digno de reseñar?

Esta investigación ha sido fruto de un esfuerzo personal y económico, al no contar con ningún tipo de ayuda o beca, con excepción de la que me prestó el editor Eliseu Climent y Acció Cultural del País Valencià, sufragándome el coste de una parte de las fotocopias de la documentación solicitada a Salamanca, por lo que deseo mostrarles mi agradecimiento, lo mismo que a los directores de la Tesis, al Tribunal, a los profesores miembros de la Comissió de la Veritat del P.V. y a tantos miembros del CEHME que me han animado y aconsejado a lo largo de todos estos años.

Esta entrevista se efectúo de forma telemática el 5 de abril de 2016.

Autores de la entrevista: Ricardo Martínez Esquivel e Yván Pozuelo Andrés, Director y Editor de REHMLAC+.

DOI: http://dx.doi.org/10.15517/rehmlac.v8i1.24288 